\title{
Rehberli Sorgulama Öğretim Modeline Dayalı Fen Öğretiminin 7. Sınıf Öğrencilerinin Bilimsel Süreç Becerileri Üzerindeki Etkisinin İncelenmesi: Kuvvet ve Enerji Ünitesi Örneği*
}

\section{Müge SAĞDIÇ ${ }^{* *}$ Hasan BAKIRCI ${ }^{* * *}$ Zeynel BOYNUKARA ${ }^{* * * *}$}

Öz: Öğretim yaklaşım ve modelleri öğrenmenin gerçekleşmesinde önemli bir yere sahiptir. Öğrencileri araştırma yapmaya yönlendirmede, onların derse aktif katılımını sağlamada ve öğrenmeyi kolaylaştırmada öğretim modellerinin büyük bir katkısı olduğu söylenebilir. $\mathrm{Bu}$ bağlamda çalışmanın amacı, rehberli sorgulama öğretim modeline dayalı fen öğretiminin ortaokul 7. sınıf öğrencilerinin bilimsel süreç becerilerine olan etkisini araştırmaktır. Çalışma deneysel desenlerden yarı deneysel yönteme göre tasarlanmıştır. Çalışma, 2017-2018 eğitimöğretim yılında Van'ın Başkale ilçesindeki bir ortaokulda öğrenim gören 40'1 kontrol ve 45'i deney grubunda olmak üzere toplam 85 yedinci sınıf öğrencisi ile yürütülmüştür. Çalışma, dört hafta sürmüştür. Dersler, deney grubunda rehberli öğretim modeline göre işlenirken, kontrol grubunda 5E öğretim modeline göre işlenmiştir. Veriler; Bilimsel Süreç Beceriler Ölçeği (BİSBÖ) aracılığıyla toplanmıştır. BİSBÖ ile elde edilen veriler, bağımlı ve bağımsız t-testi kullanılarak analiz edilmiştir. Sonuç olarak, rehberli sorgulama öğretim modeline dayalı fen öğretiminin, 7. sınıf öğrencilerinin bilimsel süreç becerileri üzerinde etkili olduğu tespit edilmiştir. $\mathrm{Bu}$ açıdan bakıldığında öğrencilerin bilimsel süreç becerilerinin gelişimi için öğretmenlerin Fen Bilimleri derslerinde rehberli sorgulama öğretimi modelini kullanmalarının uygun olacağı söylenebilir.

Anahtar Sözcükler: Rehberli sorgulama öğretim modeli, bilimsel süreç becerileri kuvvet ve enerji ünitesi, yedinci sınıf öğrencileri.

\footnotetext{
"Bu çalışma birinci yazarın yüksek lisans tezinin bir bölümünde oluşmaktadır.

**Uzman Fen Bilimleri Öğretmeni, Milli Eğitim Bakanlığı, Orcid ID: 0000-0001-7687-0350. Email: muge.sagdic@hotmail.com.

** Doç. Dr. Van Yüzüncü Y11 Üniversitesi, Eğitim Fakültesi, Orcid: 0000-0002-7142-5271, Email:hasanbakirci09@gmail.com.

${ }^{* * *}$ Dr. Öğr. Üyesi, Van Yüzüncü Y1l Üniversitesi, Eğitim Fakültesi, Orcid No: 0000-0002-0440-6281, Email: bzeynel@yahoo.com
}

Gönderim: 23.04.2019 Kabul: 28.07.2019 Yayın: 15.09.2019




\title{
The Effect of Guided Inquiry Teaching Model on the Scientific Process Skills of Students: The Case Study of Force and Energy Unit
}

\begin{abstract}
Teaching approaches and models have an important role in learning as they have the potential to channel students to research, increase their active participation and facilitate learning. The study aims to investigate the effect of guided inquiry teaching model on $7^{\text {th }}$ grade students' scientific process skills. The research employed the quasi-experimental method and it was carried out with 85 seventh grade students, 40 in control and 45 in experimental group, in a secondary school in Başkale district of Van during 2017-2018 academic year. The data collection process lasted four weeks. The guided inquiry based teaching model was used in the experimental group and 5E instructional model was used in the control group. The data were collected through the Scientific Process Skills Scale and were analysed by using dependent and independent t-test. The findings show that science teaching based on guided inquiry model has an effect on the scientific process skills of $7^{\text {th }}$ grade students. From this perspective, it can be said that it is appropriate for teachers to use guided inquiry teaching model in Science courses for the development of students' scientific process skills.
\end{abstract}

Keywords: Guided inquiry teaching model, scientific process skills, force and energy unit, $7^{\text {th }}$ grade students.

\section{Giriş}

Eğitim alanında yapılan değişikliklerin temelinde, nitelikli bireyler yetiştirmek vardır. Nitelikli bireylerin yetişmesinde, çağdaş öğrenme kuramlarının, öğretim stratejilerinin, modellerinin ve öğretmenlerin büyük rolü bulanmaktadır. Öğretmenler, etkili bir öğrenme ortamı oluşturmak için yeni öğretim yaklaşım, öğretim model ve teknikleri denemişlerdir. Öğrenme ortamında farklı öğretim yaklaşımlarının kullanılması ile öğrencilerden ve öğretmenlerden beklenen görev ve sorumluluklar da değişmiştir. Bu uygulamaların temel amacı, öğrencilerin öğrenme ortamında aktif bireyler olmasını sağlamaktır (Alkan-Dilbaz, 2013; Bökeoğlu ve Yılmaz, 2005). Böylece öğrenciler, elde ettikleri bilgileri kullanabilen, yaşam boyu öğrenmeye açık olmaları, bilgi teknolojilerinden faydalanan, yeniliğe açık olan, araştıran, sorgulayan, eleştiren ve yaratıcı düşünme gibi becerilere sahip olmaları beklenmektedir (Alkan-Dilbaz, Yanber-Yelken ve Özgelen, 2016). Öğretmenlerin sorumluluğu ise öğrencilerine zengin öğrenme ortamları sunmaktır. Yani bireysel farklılıklara sahip öğrencilerin ihtiyaç, yetenek ve koşularına göre öğretim materyalleri temin etmek ve bunların kullanılması sağlamaktır (Çelikten, Şanal ve Yeni, 2005). 
Birçok gelişmiş ve gelişmekte olan ülkelerin öğretim programlarında son yıllarda radikal değişimler olduğu görülmektedir (Lederman, Lederman ve Antink, 2013). Bu değişimlerin odak noktasında ihtiyaca uygun nitelikli bireylerin yetiştirilmesi yatmaktadır (Eş ve Sarıkaya, 2010). Bundan dolayı araştırmacılar fen öğretimi ve öğreniminin niteliğini arttırmak ve bireyleri bilim okuryazarı olarak yetiştirmek için öğretim yaklaşımları üzerinde çalışmaktadırlar (Lederman ve ark., 2013). Bu öğretim yaklaşımlarından biri de araştırmasorgulama dayalı öğrenme yaklaşımıdır (McConney, Oliver, Woods-McConney, Schibeci ve Maor, 2014). Bu yaklaşım ile öğrencilerin sorgulayıcı öğrenme becerilerini kazandıkları ve bu sayede öğrencilerde anlamlı öğrenmenin gerçekleştiği saptanmıştır (Çelik ve Çavaş, 2012). Araştırma sorgulamaya dayalı öğrenme yaklaşımının temel felsefesinde, yaşam boyu öğrenme ve fen okuryazarı bireyler yetiştirmenin var olması, bu yaklaşımın öğretim programlarında yer almasında etkili olduğu düşünülmektedir (Sağdıç ve Bakırcı, 2019).

Yaşam boyu öğrenen birey; araştıran, sorgulayan, kendine güvenen, etkili kararlar verebilen, iş birliğine açık, problem çözebilen, etkili iletişim kurabilen birey olarak tanımlanmaktadır (Milli Eğitim Bakanlığı [MEB], 2013). Bu bireyler, toplumsal sorunlarla ilgili problemlerin çözümünde kendilerini sorumlu hissederek, yaratıcı ve analitik düşünerek farklı çözümler üretebilirler. Bunun yanında; birey bilgiyi araştırır, sorgular ve zamanla değişebileceğini yaptığı araştırmalar sonucunda farkına varır. Yukarıda özellikleri verilen öğrenme yaklaşımının, araştırma-sorgulamaya dayalı öğrenme yaklaşımıdır. Bu öğrenme yaklaşımı, 2013 yılında Fen Bilimleri Dersi Öğretim Programında yer almıştır. Çünkü bu öğrenme yaklaşımının, öğrencilere 21. yüzyıl becerilerini kazandırmada etkili bir öğrenme yaklaşımı olmasıdır (MEB, 2013). Dolayısıyla öğretim programında yer alan bu yaklaşımın fen öğretimi üzerinde etkisinin araştırılmasının önemli olduğu düşünülmektedir.

Günümüzde; yeniliklere açık, araştıran, sorgulayan, bilgi ve iletişim teknolojilerini kullanabilen çok yönlü bireylere ihtiyaç duyulmaktadır. $\mathrm{Bu}$ özelliklere sahip bireyleri yetiştirmek için öğrenme ortamlarında bireysel farklılıkları dikkate alan ve farklı öğretim yöntem/tekniklerine ihtiyaç duyulmaktadır. Bu özelliklere sahip bireyleri yetiştirmek öğretim programlarının hedefleri arasında yer almaktadır (Keçeci ve Kırbağ-Zengin, 2016). Öğretim programının hedeflerini gerçekleştirmede öğretmenlere önemli görevler düşmektedir. $\mathrm{Bu}$ görevlerden bazıları, öğrenme ortamını hazırlama, gerekli araç-gereçleri temin etme ve öğrencilerin öğrenme seviyesine uygun çağdaş öğrenme kuramlarını esas alan öğrenme yaklaşımını/modelini derste kullanma olarak sıralanabilir. Son y1llarda fen öğretiminde 
kullanılan öğretim yaklaşımlarından birisi de araştırma-sorgulamaya dayalı öğrenme yaklaşımı olduğu söylenebilir.

Araştırma-sorgulamaya dayalı öğrenme yaklaşımı fen öğretiminin, öğrencilerin dünyaya daha bilimsel olarak bakmaları ve fen okuryazarı olarak yetişmeleri üzerinde etkili olması (Keçeci ve Kırbağ-Zengin, 2016); araştırmaya dayalı öğrenme yaklaşımın öğrenme ortamlarında kullanılmasıyla kavramlar, prensipler, kanunlar ve teorilerin anlaşılmasını sağlayarak, bilime karşı pozitif bilgi oluşturma ve bilimin doğası üzerinde etkili olduğu (Chippetta ve Adams, 2004); araştırma ve sorgulamaya dayalı fen öğretiminin öğrencilerin bilimsel süreç becerileri ve tutumları üzerinde etkili olduğu (Keçeci ve Kırbağ-Zengin, 2016) gibi sonuçlara ulaşılmıştır. Araştırmaya dayalı öğrenme yaklaşımının öğrencilerin FenTeknoloji-Toplum-Çevre ilişkisini kurmada etkili olduğu da tespit edilmiştir (Kızılaslan, Sözbilir ve Yaşar, 2012). Sonuç olarak araştırma-sorgulamaya dayalı öğrenme yaklaşımının; fen okuryazarlıkta, bilimsel süreç becerilerinin gelişiminde ve bilimsel bilgi türleri üzerinde etkili olması nedeniyle bu yaklaşımı esas alan rehberli sorgulama öğretim modelinin Kuvvet ve Enerji ünitesi öğretiminde etkili olacağına inanılmaktadır.

Fen Bilimleri Dersi Öğretim Programı’nın 2013 yılında uygulanmaya konulmasıyla araştırma-sorgulamaya dayalı öğrenme yaklaşımını esas alan çalışmaların hızla arttı̆̆ı görülmektedir. Ancak bu yaklaşımı temel alan öğrenme ortamlarında "Kuvvet ve Enerji" ünitesine yönelik çalışmaların sınırlı olduğu söylenebilir. Öğretim programının temel yaklaşımlarından birisinin araştırma sorgulamaya dayalı öğrenme yaklaşımı olması nedeniyle bu konuda yapılan çalışmaların öğretim programının amacının gerçekleşme düzeyi hakkında bilgi vermesi açısında önemli olduğu düşünülmektedir. Diğer taraftan birçok gelişmiş ülkenin öğretim programlarında bu yaklaşımın yer alması gerek yurtiçinde gerekse yurt dışında yapılan çalışmaların olumlu sonuçlar ortaya çıkardığı bilinen bir gerçektir. Fen öğretiminin temel amaçlarından birisinin de öğrencilere bilimsel süreç becerilerini kazandırmak olduğu düşünüldüğünde, araştırma-sorgulamaya dayalı öğrenme yaklaşımın bu becerileri üzerinde etkisinin ortaya çıkarılması açısından bu çalışmanın önemli olduğu söylenebilir. Bu bağlamda çalışmanın amacı, rehberli sorgulama öğretim modeline dayalı fen öğretiminin ortaokul 7. sınıf öğrencilerinin bilimsel süreç becerilerine olan etkisini araştırmaktır. 


\section{Yöntem}

\section{Araştırmanın Deseni}

$\mathrm{Bu}$ araştırma, deneysel desenlerden yarı deneysel yönteme göre tasarlanmıştır. $\mathrm{Bu}$ araştırma modeli, eğitim araştırmalarında tam deneysel deseninin uygulanmadığı durumlarda uygulamanın yapılacağı gruplara seçkisiz olarak atamaların yapıldığı araştırma deseni olarak adlandırılmaktadır (Çepni, 2011). Farklı deneklerden oluşan deney ve kontrol gruplarının ölçümleri karşılaştırıldığı için ilişkisiz desen, deneysel işlem öncesinde ve sonrasında bağımlı değişkenle ilgili olarak ölçüldükleri için ilişkili desen olarak bilinmektedir (Karasar, 2016). Deney grubunda rehberli sorgulama öğretim modelinin ve kontrol grubunda 5E öğretim modelinin yedinci sınıf öğrencilerinin bilimsel süreç becerileri üzerinde etkisi araştırıldığı için bu araştırmada yarı deneysel araştırma modeli kullanılmıştır.

\section{Çalışma Grubu}

Çalışma grubunu, 2017-2018 eğitim öğretim yılında Van’a bağlı Başkale ilçesindeki bir ortaokulda deney 45 ve kontrol grubunda 40 olmak üzere toplam 85 yedinci sınıf öğrencisinden oluşmaktadır. Deney grubunda, 23 kız ve 22 erkek öğrenci yer alırken; kontrol grubunda, 17 kız ve 23 erkek öğrenci yer almıştır. Çalışma grubunun belirlenmesinde kolay ulaşılabilir örneklem yöntemi tercih edilmiştir. Çünkü bu örneklem yöntemi, çalışmaya ekonomiklik, pratiklik ve hız kazandırmaktadır (Yıldırım ve Şimşek, 2011). Ayrıca çalışma grubunun belirlenmesinde araştırmacının Başkale'de görev yapıyor olmasının da etkili olduğu söylenebilir.

\section{Veri Toplama Aracı}

Bu çalışmada, Aydoğdu, Tatar, Yıldız ve Buldur (2012) tarafından geliştirilen Bilimsel Süreç Becerisi Ölçeği (BİSBÖ) kullanılmıştır. Bu ölçme aracı, 27 çoktan seçmeli sorudan oluşmaktadır. BİSBO, temel ve üst düzey becerileri ölçen sorulardan oluşmaktadır. Ölçekte, temel becerilerden, gözlem yapma, sınıflama yapma, uzay/zaman ilişkilerini kullanma, tahmin yapma, çıkarım yapma, becerilerine yönelik sorular yer almaktadır. Üst düzey becerilerden ise problem belirleme, hipotez kurma, değişkenleri belirleme ve kontrol etme, deney yapma ve verileri yorumlama becerilerine yönelik sorular yer almaktadır. Ölçekteki sorular, temel becerilere ait 9 soru ve üst düzey becerilere ait 18 soru olacak şekilde dağılmaktadır.

Bilimsel Süreç Becerileri Ölçeği (BİSBÖ)'nin güvenirliği ve geçerlilik ile ilgili çalışmalar Aydoğdu ve ark., (2012) tarafında yapılmıştır. Ölçeğin, güvenirlik katsayısı Kuder Richardson-20 (KR-20), 0.84 ve ortalama güçlüğü 0.54 olarak hesaplanmıştır. Bu değerler ölçeğin güvenilir olduğunu göstermektedir (Büyüköztürk, 2011). Ölçeğin, iç geçerliliğini 
sağlamak için iki Fen Bilimleri öğretmenine ve fen eğitiminde doktorası olan üç öğretim üyesi görüşüne başvurulmuştur. Uzman görüşleri doğrultusun ölçeğin son hali verilmiştir. BİSBÖ’deki 27 sorunun alt boyutları Tablo 1'de yer almaktadır.

\section{Tablo 1.}

Bilimsel Süreç Becerilerinin Alt Boyutları

\begin{tabular}{clc}
\hline $\begin{array}{c}\text { Bilimsel süreç } \\
\text { Becerileri }\end{array}$ & \multicolumn{1}{c}{ Alt Boyutlar } & Ölçekteki Soru Numaraları \\
\hline \multirow{4}{*}{ Temel Beceriler } & Gözlem yapma & 1,2 \\
\cline { 2 - 3 } & Słnıflama yapma & \multicolumn{1}{c}{3,4} \\
\cline { 2 - 3 } & Uzay/zaman ilişkilerini kullanma & 17,27 \\
\cline { 2 - 3 } & Tahmin yapma & 7 \\
\cline { 2 - 3 } & Çıkarım yapma & 5,6 \\
\cline { 2 - 3 } & Problemi belirleme & 16,22 \\
\hline \multirow{3}{*}{ Üst Düzey Beceriler } & Hipotez kurma & $10,11,17,23$ \\
\cline { 2 - 3 } & Değişkenleri belirleme ve kullanma & $18,19,20,24,25$ \\
\cline { 2 - 3 } & Deney yapma & $8,12,13,15,21$ \\
\cline { 2 - 3 } & Verileri yorumlama & 9,26 \\
\hline
\end{tabular}

\section{Uygulama}

Uygulama, toplam dört haftada (16 ders saati) gerçekleşmiştir. Dersler, Fen Teknoloji Laboratuvarında ve sınıfta işlenmiştir. Deney ve kontrol gruplarında dersler araştırmacı tarafından yürütülmüştür. Araştırmacının çalışmanın yürütüldüğ̈̈ okulda öğretmen olarak çalışması, iç geçerliliğinin kontrol altında tutulmasını sağlamıştır. Deney grubunda araştırmacı tarafından Kuvvet ve Enerji ünitesi bağlamında geliştirilen öğretim materyalleri rehberli sorgulama öğretim modeli kapsamında kullanılırken, kontrol grubunda ise Fen Bilimleri dersinde yer alan mevcut öğretim materyalleri 5E öğretim modeli temelinde dersler işlenmiştir. Kuvvet ve Enerji ünitesindeki “Enerji Dönüşümleri” konusunun uygulama süreci Tablo 2'de ayrıntılı olarak açıklanmıştır. 
Tablo 2.

Kontrol ve Deney Grubu İçin ‘Enerji Dönüşüm Konusu İle İlgili Uygulama Süreci

Kontrol Grubu

Dersler, mevcut öğretim modeline göre yapılmıştır.

Girme aşaması: Öğretmen, öğrencilere kinetik ve potansiyel enerji türlerinin birbirine nasıl dönüştüğünü sorarak derse başlandı. Öğrencilerin bu soruyla ilgili cevapları alındı. Öğretmen, bir etkinlik yaptıktan sonra cevapları bir daha tartışalım deyip etkinliğe geçildi.

Keşfetme aşaması: Öğrenciler beşerli gruplara ayrıldı. Daha sonra ilgili etkinliğe geçildi.

Malzemeler: 3 adet eğik düzlem tahtası, 3 adet farklı kütlelerdeki oyuncak araba, yükseklik oluşturmak için ders kitapları, cetvel.

Yapılışı: Aynı anda arabaları kuvvet uygulamadan sadece serbest birakmaların sonra aldıkları yolları cetvelle ölçmeleri istendi. Daha sonra farklı kütlelerdeki arabalara yükseklikleri değiştirerek aynı işlemler uygulandı. Bulunan sonuçlar not edildi ve tartışıld.

Açıklama aşaması: Öğrencilerle yapılan etkinliğin sonucunu tartışıldı. Öğretmen ise ortaya çıkan eksiklikleri ipuçları vererek bulmalarını istedi.

Derinleştirme aşaması: Peki arkadaşlar hayatımızda bu enerji türlerinin birbirine dönüşmesi bize ne gibi kolaylık sağlar?, Enerji nasıl korunur? Soruları soruldu. Günlük hayattan farklı örnekler vermeleri istendi.

Değerlendirme aşaması: Öğrencilerin bu konuyu anlayıp anlamadığını öğrenmek için ders kitabındaki etkinlik soruları cevaplandırıld.
Deney Grubu

Dersler, rehberli sorgulama öğretim modeline göre yapılmıştır.

Sorgulama: Öğrencilere kinetik ve potansiyel enerjinin birbirine dönüşmesiyle ilgili fotoğraflar gösterildi. Öğrencilere malzemeler dağıtıldı. Bu malzemeler ile ne yapılacağı sorusu soruldu.

Var olan bilgiyi açığa çıkarma: Öğrencilerden bu soru hakkındaki görüşlerini ortaya çıkarmak için beyin firtınası tekniği uygulandı.

Tahminde bulunma: Öğrenciler sorgulama basamağında sorulan bu malzemelerle ne yapacağı? Sorusunun cevaplarını nedenleriyle birlikte tahminde bulundular. Kinetik ve potansiyel enerjinin dönüşümüyle ilgili deney yapmaları istendi. Malzemeler: 3 adet eğik düzlem tahtası, 3 adet farklı kütlelerdeki oyuncak araba, yükseklik oluşturmak için ders kitapları, cetvel.

Yapılış1: Aynı anda arabaları kuvvet uygulamadan sadece serbest birakmalarını sonra aldıkları yolları cetvelle ölçmeleri istendi. Daha sonra farklı kütlelerdeki arabalara yükseklikleri değiştirerek aynı işlemler uygulandı. Bulunan sonuçlar not edildi ve tartış1ld.

Uygulamayı planlama ve yapma: Ögretmen bu araştırmayı çözmeleri için deney yönergesi vererek bir palan çıkarmalarını ve planı uygulamalarını istedi.

Yorum yapma ve sonuçları sunma: Öğrenciler deneyi yaparken süreci gözlemlediler ve analiz ettiler. Öğrenciler deneylerini nasıl tasarladıklarını diğer gruplar ile paylaştılar. Hangi deneyin uygun olduğu öğrencilerle tartışılarak süreç sonlandirild. 


\section{Verilerin Analizi}

Bilimsel Süreç Becerileri Ölçeği (BİSBÖ)’nden elde edilen veriler; SPSS 21.0 programına girilmiş ve gerekli parametrelerin incelenmiştir. BİSBÖ’ de her bir doğru cevaba bir puan, yanlış cevaba ise sıfır puan verilmiştir. BİSBÖ’den alınabilecek en yüksek puan 27 ve en düşük puan sıfırdır. Daha sonra öğrencilerin her bir soruda almış olduğu puan ve test toplam puanları hesaplanmıştır. Yapılan hesaplamalar sonucunda, BİSBÖ ile elde edilen verilerin, homojen dağılım göstermesi ve örneklem sayısının 30'un üzerinde olmasından dolayı parametrik testlerin kullanılmasına karar verilmiştir. Deney ve kontrol gruplarını karşılaştırmalarda parametrik testlerden bağımsız t-testi kullanılırken, grupların kendi içinde karşılaştırmalarında bağımlı t-testi tercih edilmiştir.

\section{Bulgular}

Deney ve kontrol grubunun BİSBÖ ön test ve son test arasındaki bağımsız t-testi sonuçları Tablo 3’te sunulmuştur.

Tablo 3.

Kontrol ve Deney Grubunun BİSBÖ Ön ve Son Test Puanları Arasındaki Anlamlılığa İlişkin Bağımsız T-Testi Sonuçları

\begin{tabular}{rllccccc}
\hline Test & Grup & $\mathbf{N}$ & $\bar{X}$ & Ss & Sd & t & \multicolumn{1}{|c}{ P } \\
\hline \multirow{2}{*}{ Ön Test } & Deney & 45 & 8.66 & 2.82 & \multirow{2}{*}{83} & \multirow{2}{*}{0.876} & \multirow{2}{*}{384} \\
\cline { 2 - 5 } & Kontrol & 40 & 8.12 & 2.87 & & & \multirow{2}{*}{03} \\
\multirow{2}{*}{ Son Test } & Deney & 45 & 11.17 & 3.44 & \multirow{2}{*}{2.169} & \multirow{2}{*}{.033} \\
\cline { 2 - 5 } & Kontrol & 40 & 9.60 & 3.23 & & & \\
\hline
\end{tabular}

Tablo 3’te görüldüğü gibi deney ve kontrol gruplarının ön test puanları için yapılan bağımsız t-testi sonucunda gruplar arasında bilimsel süreç becerileri ölçeğinden elde edilen puanlar açısından istatistiksel olarak anlamlı bir fark bulunamamıştır $\left[\mathrm{t}_{(83)}=0.876, \mathrm{p}>0.05\right]$. Bu bulgu, uygulama öncesinde grupların bilimsel süreç becerilerine ait ön bilgilerinin birbirine yakın olduklarını göstermektedir.

Tablo 3 incelendiğinde deney ve kontrol gruplarının son test puanları için yapılan bağımsız t-testi sonucunda gruplar arasında bilimsel süreç becerileri ölçeğinden elde edilen puanlar açısından istatistiksel olarak anlamlı bir fark bulunmuştur $\left[\mathrm{t}_{(83)}=2.169, \mathrm{p}<0.05\right] . \mathrm{Bu}$ anlamlı farkın deney grubu lehine olduğu görülmektedir.

Tablo 4'te kontrol ve deney gruplarının ön test ve son test puanlarının bağımlı t-testi ile karşılaştırılması verilmiştir. 
Tablo 4.

Deney ve Kontrol Gruplarının BİSBÖ Ön ve Son Test Arasındaki Anlamlılığa İlişkin Bağımlı T-Testi Sonuçları

\begin{tabular}{cccccccc}
\hline Grup & Test & $\mathbf{N}$ & $\bar{X}$ & Ss & sd & t & P \\
\hline \multirow{2}{*}{ Deney } & Ön Test & 45 & 8.66 & 2.82 & \multirow{2}{*}{44} & -3.874 & \multirow{2}{*}{.000} \\
\cline { 2 - 6 } Kon Test & 45 & 11.17 & 3.44 & & & \\
\multirow{2}{*}{ Kontrol } & Ön Test & 40 & 8.12 & 2.87 & \multirow{2}{*}{39} & -2.512 & \multirow{2}{*}{016} \\
\cline { 2 - 6 } & Son Test & 40 & 9.60 & 3.23 & & &
\end{tabular}

Tablo 4'te görüldügü gibi deney grubuna ait ön test ve son test puanları için yapılan bağımlı t-testi sonucunda ön test ve son test puanları arasında bilimsel süreç becerileri açısından son test puanları lehinde istatistiksel olarak anlamlı bir farklılık bulunmuştur $\left[\mathrm{t}_{(44)}=-3.874\right.$, $\mathrm{p}<.0 .05]$. Kontrol grubuna ait ön test ve son test puanları bağımlı t-testi ile incelendiğinde ise ön test ve son test puanları arasında bilimsel süreç becerileri puanları açısından son test puanları lehinde istatistiksel olarak anlamlı bir farklılık bulunmuştur [ $\left.\mathrm{t}_{(39)}=-2.512, \mathrm{p}<0.05\right]$.

Deney grubu öğrencilerinin cinsiyet açısından bilimsel süreç becerileri ölçeğine ait ön ve son test puanlarının karşılaştırılmasına ait bağımlı t-testi sonuçları Tablo 5'te sunulmuştur.

Tablo 5.

Deney Grubu Öğrencilerinin Bilimsel Süreç Becerileri Ölçeği Ön ve Son Test Puanlarının Cinsiyete Göre Karşılaştırılmasına İlişkin Bağımlı T-testi Sonuçları

\begin{tabular}{|c|c|c|c|c|c|c|c|}
\hline Cinsiyet & Test & $\mathbf{N}$ & $\bar{X}$ & Ss & Sd & $\mathbf{t}$ & $\mathbf{P}$ \\
\hline \multirow{2}{*}{ Kız } & Ön Test & 24 & 8.83 & 2.88 & \multirow{2}{*}{23} & \multirow{2}{*}{-8.076} & \multirow{2}{*}{$.000^{*}$} \\
\hline & Son Test & 24 & 12.75 & 2.80 & & & \\
\hline \multirow{2}{*}{ Erkek } & Ön Test & 21 & 8.47 & 2.80 & \multirow{2}{*}{20} & \multirow{2}{*}{-0.964} & \multirow{2}{*}{.346} \\
\hline & Son Test & 21 & 9.38 & 3.27 & & & \\
\hline
\end{tabular}

Tablo 5 incelendiğinde, deney grubunda yer alan kız öğrencilerin bilimsel süreç beceri ölçeği, ön ve son test puanları arasında anlamlı bir farkın olduğu, bu farkın ise son test lehinde olduğu görülmektedir $\left[\mathrm{t}_{(23)}=-8.076, \mathrm{p}<.0 .05\right]$. Diğer taraftan deney grubundaki erkek öğrencilerin bilimsel süreç becerileri ölçeği, ön ve son test puanları arasında anlamlı bir farkın olmadığı tespit edilmiştir $\left[\mathrm{t}_{(23)}=-0.964, \mathrm{p}>0.05\right]$.

Kontrol grubu öğrencilerinin cinsiyet açısından bilimsel süreç becerileri ölçeğine ait ön ve son test puanlarının karşılaştırılmasına ait bağımlı t-testi sonuçları Tablo 6'da sunulmuştur. 
ISSN: 1305-020

\section{Tablo 6.}

Kontrol Grubu Öğrencilerinin Bilimsel Süreç Becerileri Ölçeği Ön ve Son Test Puanlarının Cinsiyete Göre Karşılaştırılmasına İlişkin Bağımlı T-testi Sonuçları

\begin{tabular}{|c|c|c|c|c|c|c|c|}
\hline Cinsiyet & Test & $\mathbf{N}$ & $\bar{X}$ & Ss & sd & $\mathbf{t}$ & $\mathbf{P}$ \\
\hline \multirow{2}{*}{ Kız } & Ön Test & 17 & 8.29 & 2.51 & \multirow{2}{*}{16} & \multirow{2}{*}{-3.933} & \multirow{2}{*}{$.001^{*}$} \\
\hline & Son Test & 17 & 10.11 & 2.36 & & & \\
\hline \multirow{2}{*}{ Erkek } & Ön Test & 23 & 8.00 & 3.16 & \multirow{2}{*}{22} & \multirow{2}{*}{-1.255} & \multirow{2}{*}{.223} \\
\hline & Son Test & 23 & 9.21 & 3.75 & & & \\
\hline
\end{tabular}

Tablo 6 incelendiğinde, kontrol grubunda yer alan kız öğrencilerinin bilimsel süreç becerileri ölçeği, ön ve son test puanları arasında anlamlı bir fark olduğu, bu farkın ise son test lehinde olduğu görülmektedir $\left[\mathrm{t}_{(16)}=-3.933, \mathrm{p}<.05\right]$. Diğer taraftan kontrol grubundaki erkek öğrencilerinin bilimsel süreç becerileri ölçeği, ön ve son test puanları arasında anlamlı bir farkın olmadiğ 1 tespit edilmiştir $\left[\mathrm{t}_{(22)}=-1.255, \mathrm{p}>.05\right]$.

\section{Tartışma ve Sonuç}

$\mathrm{Bu}$ çalışmada, rehberli sorgulama öğretim modelinin yedinci sınıf öğrencilerinin bilimsel süreç becerileri üzerindeki yansımalarını ortaya çıkarmak amaçlanmıştır. Fen eğitiminin temel amaçlarından birisi de öğrencilere bilimsel süreç becerilerini kazandırmaktır. Çünkü bilimsel süreç becerisini kazanamayan bir öğrenci bilgiye nasıl ulaşacağını, bilgiyi nasıl yapılandıracağını ve nasıl etkili bir deney ortamında görev alacağını bilmeyecektir. Deney ve kontrol grubunda yapılan uygulamaların yedinci sınıf öğrencilerin bilimsel süreç becerileri üzerinde etkisi alan yazın perspektifinde tartışılmıştır.

Deney ve kontrol grubuna ait ön test ve son test puanları arasında anlamlı bir farkın olduğu, bu farkın her iki grupta son test lehine olduğu tespit edilmiştir. Bu bulgu deney grubunda uygulanan rehberli sorgulama öğretim modeli ile kontrol grubunda uygulanan 5E öğretim modelinin öğrencilerin bilimsel süreç becerileri üzerinde etkili olduğunu göstermektedir. Deney grubundaki artışta, yapılan deneylerin bilimsel süreç becerilerinin basamaklarının kullanılarak yapılması ve deneyler sonunda yapılan tartışmaların etkili olduğu düşünülmektedir. Buna karşı kontrol grubunda keşfetme basamağında yapılan etkinliklerde bilimsel süreç becerilerinin basamaklarının kullanılması ve derinleştirme aşamasında bilim insanlarının bilimsel süreç becerilerini kullandığına dair yapılan sınıf tartışmasının etkili olduğu söylenebilir. Alan yazın incelendiğinde araştırma sorgulamaya dayalı öğreneme yaklaşımına dayalı öğrenme ortamları ve 5E öğretim modeline göre tasarlanan öğrenme ortamlarının farklı kademedeki öğrencilerin bilimsel süreç becerileri üzerindeki etkisinin olduğuna dair birçok çalışma bulunmaktadır 
(Karapınar, 2016; Kaya ve Y1lmaz, 2016; Öztürk-Geren ve Dökme, 2015; Ürey ve Çalık, 2008). $\mathrm{Bu}$ çalışmada elde edilen bulgular alan yazındaki elde edilen bulgularla örtüşmektedir. Karapınar (2016), araştırma sorgulamaya dayalı öğrenme ortamının öğretmen adaylarının bilimsel süreç becerileri üzerinde etkili olduğu sonucuna ulaşmıştır. Aynı şekilde Kaya ve Yılmaz (2016), ortaokul 7. sınıf öğrencileriyle yürütmüş oldukları çalışmada açık sorgulamaya dayalı öğrenme yaklaşımının öğrencilerin bilimsel süreç becerileri üzerinde etkili olduğunu saptamışlardır.

Deney ve kontrol gruplarının son test puanları için yapılan bağımsız t-testi sonucunda anlamlı bir fark bulunmuştur $\left[\mathrm{t}_{(83)}=2.169, \mathrm{p}<0.05\right]$. Bu anlamlı farkın deney grubu lehine olduğu görülmektedir. Deney ve kontrol grubu kıyaslandığında, deney grubunda uygulanan rehberli sorgulama modeline dayalı fen öğretiminin kontrol grubunda uygulanan 5E esaslı fen öğretimine göre bilimsel süreç becerileri üzerinde daha etkili olduğu söylenebilir. Deney grubundaki bu farkın deney grubundaki öğrencilerin okul dışında yaptıkları araştırmadan kaynaklandığına inanılmaktadır. Arslan (2013), model tabanlı araştırma sorgulamaya dayalı öğrenme ortamı tasarlayarak öğretmen adaylarının bilimsel süreç becerilerini araştırmıştır. Çalışmanın sonucunda, model tabanlı araştırma sorgulamaya dayalı öğrenme yaklaşımın öğretmen adaylarının bilimsel süreç becerileri üzerinde etkili olduğu sonucuna ulaşmıştır. Yine yapılan başka bir çalışmada Çelik ve Çavaş (2012), araştırma dayalı öğrenme yaklaşımının bilimsel süreç becerileri, akademik başarı ve öğrencilerin derse karşı tutumları üzerinde etkili olduğu sonucuna varmışlardır.

Deney ve kontrol grubunda yer alan kız öğrencilerin bilimsel süreç becerileri ölçeğinden elde ettikleri ön ve son test puanları arasında anlamlı bir fark olduğu, bu farkın ise son test lehinde olduğu görülmektedir [bkz. Tablo 5 ve Tablo 6]. Bu bulgu, deney grubunda uygulanan rehberli sorgulama modeli ve kontrol grubunda uygulanan 5E öğretim modelinin kız öğrencilerin bilimsel süreç becerileri üzerinde etkili olduğunu göstermektedir. Diğer taraftan deney ve kontrol grubundaki erkek öğrencilerin bilimsel süreç becerileri ölçeği ön ve son test puanları arasında anlamlı bir farkın olmadığı tespit edilmiştir [bkz. Tablo 4 ve Tablo 5]. Kız öğrencilerin bilimsel süreç becerileri üzerindeki etkinin daha fazla olması ise verilen ödevlerde kız öğrencilerinin sorumluluk duygusunun erkeklere göre daha fazla olması, çalışmanın kırsal bir kesimde yapılmasından dolayı kız öğrencilerin okumada daha istekli olmalarından kaynaklanmış olabilir. 


\section{Öneriler}

Rehberli sorgulama öğretim modelinin bilimsel süreç becerileri üzerinde etkisinin daha net olarak görülebilmesi için Fen Bilimleri dersinin diğer ünitelerinde ve farklı öğrenim seviyesindeki öğrenciler ile çalışmalar yürütülmelidir.

$\mathrm{Bu}$ çalışmada, nicel veri toplama aracı yardımıyla veriler toplanmıştır. Yapılacak olan diğer çalışmalarda veri toplama aracı olarak, gözlem ve yarı yapılandırılmış mülakatın kullanıldığı nitel yaklaşımlı çalışmaların yapılması önerilmektedir.

Rehberli sorgulama öğretim modelinin etkili uygulanması için öğrencilerin araştırma ve sorgulama becerilerinin geliştirilmesine yönelik farklı öğretim materyallerinin geliştirilmesinin iyi olacağı düşünülmektedir.

Rehberli sorgulama öğretim modelinde ön plana çıkan bileşenlerden biri olan araştırma ve sorgulama becerileridir. Bundan dolayı öğrencilerin araştırma ve sorgulama becerilerini ölçen ölçme araçlarının geliştirilmesi ve kullanılması önerilmektedir. Böylece rehberli sorgulama öğretim modelinin bilimsel süreç becerileri üzerine olan etkisi daha net olarak ortaya çıkması sağlanabilir.

\section{Makalenin Bilimdeki Konumu}

Matematik ve Fen Bilimleri Eğitimi Bölümü/Fen Bilgisi Eğitimi

\section{Makalenin Bilimdeki Özgünlüğü}

Fen eğitiminin temel amaçlarından birisi de öğrencilere bilimsel süreç becerilerini kazandırmak olduğu söylenebilir. Bu beceriler, öğrencilerin öğrenme ortamına aktif katılımını sağlamada, sorumluluk alma duygusu kazanmalarında ve öğrenmeyi kolaylaştırmada büyük öneme sahiptir. Bundan dolayı fen öğretiminde bu becerileri kazandırmada etkili öğretim model ve yaklaşımlar kullanılmaktadır. $\mathrm{Bu}$ öğretim modellerinden birisinin de araştırma sorgulama yaklaşımını esas alan rehberli sorgulama öğretim modelidir. Alan yazın incelendiğinde, rehberli sorgulama öğretim modelinin bilimsel süreç becerileri üzerindeki etkisi odaklanan çalışmalarının sınırlı olduğu anlaşılmıştır. Dolayısıyla çalışmanın sonuçları bu anlamda alan yazına katkı sağlayacağı düşünülmektedir. Bunun yanında öğrencilerin bilimsel süreç becerilerini geliştirmede etkili olan öğretim modellerinin fen öğretiminde kullanımının öğretim programının amacına hizmet edeceği de söylenebilir. 


\section{Kaynaklar}

Alkan-Dilbaz, G. (2013). Araştırma temelli öğrenmenin tutum, akademik başarı, problem çözme ve araştırma becerilerine etkisi. Yayımlanmamış Yüksek Lisans Tezi, Eğitim Bilimleri Enstitüsü, Mersin Üniversitesi, Mersin.

Alkan-Dilbaz, G., Yanpar Yelken, T. ve Özgelen, S. (2013). Araştırma temelli öğrenmenin ilköğretim öğrencileri üzerindeki etkileri. Fırat Üniversitesi Sosyal Bilimler Dergisi, 23 (1), 89-103.

Arslan, A. (2013). Araştırma-sorgulama ve model tabanlı araştırma-sorgulama ortamlarında ögretmen adaylarının bilimsel süreç becerilerinin ve kavramsal değişim süreçlerinin incelenmesi. Yayınlanmamış Yüksek Lisans Tezi, Marmara Üniversitesi Eğitim Bilimleri Enstitüsü, İstanbul.

Bakırcı, H. ve Sağdıç, M. (2019). Rehberli sorgulama öğretim modelinin 7. sınıf öğrencilerinin FeTeMM tutumları üzerindeki etkisi. Afyon Kocatepe Üniversitesi Sosyal Bilimler Dergisi (Değerlendirmede).

Bökeoğlu, O. Ç. ve Y1lmaz, A. G. K. (2005). Üniversite öğrencilerinin eleştirel düşünmeye yönelik tutumları ile araştırma kaygıları arasındaki ilişki. Kuram ve Uygulamada Eğitim Yönetimi, 41(41), 47-67.

Büyüköztürk, Ş. (2011). Sosyal bilimler için veri analiz el kitabı. Ankara: Pegem Akademi Yayınc1lık.

Chippetta, E. L., \& Adams, A. D. (2004). Inquiry-based instruction. The Science Teacher, 71/2, 46-50.

Çelik, K. ve Çavaş, B. (2012). Canlılarda üreme büyüme ve gelişme ünitesinin araştırmaya dayalı öğrenme yöntemi ile işlenmesinin öğrencilerin akademik başarılarına bilimsel süreç becerilerine ve fen ve teknoloji dersine yönelik tutumlarına etkisi. Ege Ĕ̆itim Dergisi, 13(2), 50-75. 
Çelikten, M., Şanal, M. ve Yeni, Y. (2005). Öğretmenlik mesleği ve özellikleri. Erciyes Üniversitesi Sosyal Bilimler Enstitüsü Dergisi, 19 (2), 207-237.

Çepni, S. (2011). Araştırma ve proje çalışmalarına giriş. Trabzon: Celepler Matbaacılık.

Eş, H. ve Sarıkaya, M. (2010). Türkiye ve İrlanda fen öğretimi programlarının karşılaştırılması. İlköğretim Online, 9(3). 1092-1105.

Karapınar, A. (2016). Sorgulamaya dayalı öğrenme ortamının öğretmen adaylarının bilimsel süreç becerileri, sorgulama becerileri ve bilimsel düşünme yetenekleri üzerindeki etkisi. Yayımlanmamış Yüksek Lisans Tezi, Eğitim Bilimleri Enstitüsü, Celal Bayar Üniversitesi, Manisa.

Karasar, N. (2016). Bilimsel araştırma yöntemleri: Kavramlar teknikler ilkeler. Ankara: Nobel Akademik Yayınc1lık.

Kaya, G. ve Yılmaz, S. (2016). Açık sorgulamaya dayalı öğrenmenin öğrencilerin başarısına ve bilimsel süreç becerilerinin gelişimine etkisi. Hacettepe Üniversitesi Eğitim Fakültesi Dergisi, 31(2), 300-318.

Keçeci, G. ve Kırbağ-Zengin, F. (2017). Öğrencilerin araştırma sorgulamaya dayalı fen öğrenimi hakkındaki görüşleri. Turkish Studies, 12(4), 313-326.

Kızılaslan, A., Sözbilir, M. ve Yaşar, M. D. (2012). Inquiry based teaching in Turkey: A content analysis of research reports. International Journal of Environmental and Science Education, 7(4), 599-617.

Lederman, N. G., Lederman, J. S., \& Antink, A. (2013). Nature of science and scientific inquiry as contexts for the learning of science and achievement of scientific literacy. International Journal of Education in Mathematics, Science and Technology, 1(3), 138-147.

McConney, A., Oliver, M. C., Woods-McConney, A., Schibeci, R., \& Maor, D. (2014). Inquiry, engagement, and literacy in science: A retrospective, cross-national analysis using PISA 2006. Science Education, 98(6), 963-980. 
Millî Eğitim Bakanlığı (2013). Illkögretim kurumları fen bilimleri dersi (3- 8. sinıflar) öğretim programı. Ankara: Devlet Kitapları Basım Evi.

Öztürk-Geren, N. ve Dökme, İ. (2015). 5E öğrenme modeline dayalı etkinliklerinin öğrencilerin bilimsel süreç becerileri ve akademik başarılarına etkisi. Mersin Üniversitesi Eğitim Fakültesi Dergisi, 11(1). 76-95.

Ürey, M. ve Çalık, M. (2008). Combining different conceptual change methods within 5E model: A sample teaching design of cell concept and its organelles. Asia-Pacific Forum on Science Learning \& Teaching 9(2), 1-15.

Yıldırım, A. ve Şimşek, H. (2013). Sosyal bilimlerde nitel araştırma yöntemleri. Ankara: Seçkin Yayıncılık. 


\section{Summary}

\section{Introduction}

Nowadays, there is a need for multi-faceted individuals who are open to innovation, researching, questioning and using information and communication technologies. Raising such individual necessitates using different teaching methods / techniques that consider individual differences in learning environments. To educate individuals with these characteristics is among the goals of the curriculum (Keçeci and Kırbağ-Zengin, 2016). Turkey has changed Science Teaching Program. One of these changes was to adopt research and inquiry-based learning in the curriculum. This is because this learning approach is an effective learning approach for students to acquire $21^{\text {st }}$ century skills (MEB, 2013).

The studies based on research inquiry based learning approach have increased rapidly with the introduction of Science Teaching Course Program into practice in 2013. However, the studies on the Force and Energy unit in the learning environments based on this approach are limited. Since one of the basic approaches of the curriculum is a research-based learning approach, studies on this subject important in terms of providing information about the extent aims and learning outcomes of the curriculum are achieved. On the other hand, the use of this approach in many developed countries' curriculum have positive implications. Considering that one of the main objectives of science teaching is to provide students with scientific process skills, it can be said that this study is important in terms of exploring the effect of research inquiry-based learning approach on these skills.

\section{Method}

This study investigates the effect of the guided inquiry teaching model in the experimental group and the $5 \mathrm{E}$ teaching model of the control group on the scientific process skills of the seventh-grade students. Therefore, a quasi-experimental research model has been used. The participants of this research are 85 students (45 in experiment group and 40 in control group) studying in Van Başkale during 2017-2018 academic year. The Scientific Process Skills Scale developed by Aydogdu, Tatar, Yildiz and Buldur (2012) was used. The scale consists of 27 multiple choice questions. In the comparison of experimental and control groups, independent of parametric t-tests were used. The dependent t-test was preferred in comparison amongst the groups.

\section{Findings}

As shown in Table 2, there was no statistically significant difference between the groups in terms the pre-test scores of the scientific process skills scale $\left[\mathrm{t}_{(83)}=0.876, \mathrm{p}>0.05\right]$. This 
finding shows that the prior knowledge of the scientific process skills of the groups is close to each other before the intervention study starts. Independent t-test results of post-tests score of both groups show that there is a statistically significant difference in the scientific process skills of students $\left[\mathrm{t}_{(83)}=2.169, \mathrm{p}<0.05\right]$. This significant difference is observed in favor of the experimental group. As seen in Table 3, there was a significant difference between the pre-test and post-test scores in terms of scientific process skills as a result of the dependent t-test of the pre-test and post-test scores of the experimental group. $\left[\mathrm{t}_{(44)}=-3.874, \mathrm{p}<.0 .05\right]$. When the pretest and post-test scores of the control group were examined by dependent t-test, a statistically significant difference was found between the pre-test and post-test scores in terms of scientific process skills scores $\left[\mathrm{t}_{(39)}=-2.512, \mathrm{p}<0.05\right]$.

\section{Discussion and Results}

There was a significant difference between the pre-test and post-test scores of the experimental and control groups, and this difference was found to be in favour of the post-test in both groups. This finding shows that the guided inquiry teaching model used in the experimental group and the 5E teaching model in the control group were effective on the students' scientific process skills. Experiments conducted in the experimental group using the steps of scientific process skills and discussion held at the end of the experiments are thought to be effective. The discussion on the use of scientific process skills at the stage of scientific process skills and the use of scientific process skills were effective in the exploration stage in the control group. When the literature is examined, there are many studies about the learning environments based on research inquiry-based learning approach and the effect of learning environments designed according to the $5 \mathrm{E}$ teaching model on the students' scientific process skills (Karapınar, 2016; Kaya \& Y1lmaz, 2016; Öztürk-Geren \& Dökme, 2015). The findings of this research echo the findings of the literature. Karapınar (2016) concluded that researchbased learning environment has an impact on the scientific process skills of teacher candidates. Similarly, Kaya and Y1lmaz (2016) found that open questioning-based learning approach was effective on students' scientific process skills. 